\section{Recuperação de larvas de Toxocara canis de tecidos de camundongo}

\author{
Recovery of Toxocara canis larvae from mouse tissue
}

Cáris Maroni NUNES'; Saemi OGASSAWARA²

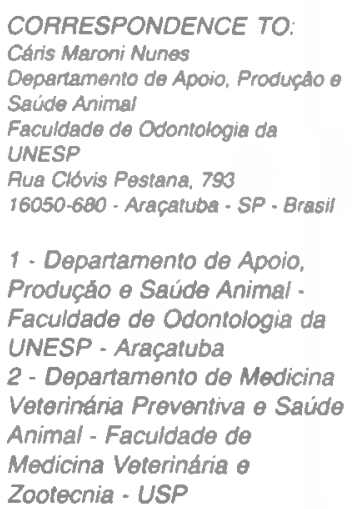

\title{
RESUMO
}

Foram avaliadas duas técnicas de recuperação de larvas de Toxocara canis em hospedeiro paratênico: digestão enzimática $\theta$ homogeneizaçāo. Vinte camundongos foram oralmente inoculados com 1.000 ovos de Toxocara canis; após 44-46 horas procedeuse à recuperação das larvas do parasito no fígado e pulmões dos animais. O fígado apresentou maior número de larvas quando comparado aos pulmōes. A técnica de homogeneizaçāo, quando comparada à técnica de digestāo, revelou-se mais eficiente para a recuperaçāo de larvas, independentemente do órgāo avaliado.

UNITERMOS: Toxocara canis; Larva migrans visceral; Larvas; Camundongos; Tecidos de animal; Técnica; Recuperação.

\section{INTRODUÇĀO}

A Larva migrans visceral (LMV), síndrome clínica decorrente da migração somática de larvas de nematóides em humanos, tem sido reconhecida como um problema emergente em saúde pública (Schantz; Glickman9 , 1983).

Com o intuito de conhecer melhor aspectos relacionados com a patogenia, imunologia e terapêutica dessa síndrome, vários estudos têm sido realizados em hospedeiros paratênicos.

A infecção experimental de camundongos com Toxocara canis constitui um dos melhores modelos biológicos para o estudo da Larva migrans visceral (Piergili et al $.^{8}, 1989$ ); a recuperação de larvas desse parasito nos diferentes tecidos é um dos principais parâmetros utilizados para avaliar a intensidade, a distribuiçāo e outros aspectos relacionados com a infecçāo. Diferentes técnicas de recuperação baseadas na liberação mecânica da larva associada à digestāo de tecidos têm sido recomendadas ${ }^{1,2,7}$.

O objetivo do presente trabalho foi avaliar o desempenho de uma técnica baseada na homogeneização para a liberaçāo mecânica das larvas presentes em tecidos, utilizando-se o camundongo como hospedeiro paratênico.

\section{MATERIAL E MÉTODO}

Vinte camundongos (Suíço albino) com idades entre 30 e 40 dias e peso médio de 30 gramas foram inoculados, com auxilio de agulha de ponta romba, por via intragástrica, com uma suspensão fecal contendo 1.000 ovos de Toxocara canis (volume de 0,3-0,4 ml), os quais apresentavam em seu interior a larva infectante. Os animais foram mantidos em gaiolas individuais e alimentados com ração comercial. Como grupo-controle, utilizaram-se 4 camundongos que foram tratados em iguais condiçōes.

Após um período de 44 a 46 horas da inoculação. os animais foram sacrificados com éter sulfúrico, para a retirada do fígado e pulmōes, e foram submetidos a uma das técnicas citadas a seguir, utilizando-se 10 animais para cada técnica:

A- Digestão com solução ácida de pepsina $1 \%$ (Sprent ${ }^{10}, 1952$, modificada por Moreira', 1972)

Pulmões e fígado colocados separadamente em placas de Petri, adicionados de soluçāo fisiológica $0,85 \%$ e fragmentados com tesoura e bisturi. Adicionou-se igual volume de solução ácida de pepsina a $1 \%$ $(\mathrm{pH}=1,5) \mathrm{e}$, após mistura adequada, incubou-se a $37^{\circ} \mathrm{C}$ por 3 horas. Passado este período procedeu-se à coagem, em coador de chá e adicionou-se soluçāo fisiológica, para se obter um volume final de $50 \mathrm{ml}$. O coado, acondicionado em tubo cônico, foi centrifugado a $700 \mathrm{~g}$ por 10 minutos; o sobrenadante foi descartado e o volume de $1 \mathrm{ml}$ do sedimento foi examinado entre lâmina e lamínula, ao microscópio óptico com aumento de $100 \mathrm{x}$, para a observação de larvas.

\section{B-Homogeneizaçāo}

Os órgāos retirados dos animais foram adicionados de $30 \mathrm{ml}$ de solução fisiológica e submetidos a trituração em homogeneizador de tecido (Omni Mixer - Sorvall), a $2.000 \mathrm{rpm}$ por minuto, para que houvesse a liberação das larvas dos tecidos. Após a passagem em coador, ajustou-se o volume para $50 \mathrm{ml}$ e procedeu-se da maneira acima descrita.

\section{ANÁLISE ESTATÍSTICA}

Os dados observados foram normalizados para posterior análise estatística, tendo sido usada a transformação $\sqrt{n^{2} \text { de larvas }+0,50}$. Para avaliar as diferenças no número de larvas recuperadas segundo as diferentes técnicas e tecidos, utilizou-se Análise de Variância a dois critérios e, posteriormente, o Teste de Tukey. Adotou-se um nível de significância igual a 5\%. 


\section{RESULTADOS E DISCUSSÃO}

O número de larvas recuperadlas após a realização de cada uma das técnicas descritas e para cada un dos órgãos avaliados pode ser observado na Tàb. I, juntamente com as medidas de posiçăo: média (x) e desvio padrão (s). Nos animais do grupo-controle nào foi observada presençáa de larvas nos órgāos avaliados.

Os resultados obtidos permitem observar que o fígado, quando comparado aos pulmóes. apresentou número médio de larvas maior, o qual foi estatisticamente significante $(P<0,05)$, independentemente da técnica empregadá.

O maior número de larvas recuperadas a partir do tecido hepático está de acorde com as observaçòes de Oshima? $(1961)$. o qual observou que. no período de 44-48 horas pós-inoculação, a maioria das larvals de Texocara canis se encontrava no lígado e. secundariamente, nos pulmòes.

Comparando-se a técnica de homogeneização com a técnica de digestão, observa-se que o número médio de recuperação de larvas foi maior e estatisticamente significante $(P<0,(15)$ quando se utilizou a técnica de homogeneização, independentemente do órgào avaliado. revelando-se, portanto. mais eficiente para a recuperaçăo de larvass.

Além de ser uma técnica de maior praticidade e de lácil execução, é menos custosa, já que náo exige o uso de enzimas digestivas, razāo pela qual sugerimos o uso em estudos que avaliem aspectos relacionados à infecção de Toxocara canis. baseando-se na recuperação de larvas de órgàos de camundongos. particularmente naqueles cuja análise é feita nos primeiros dias pós-infecção quando ainda não há intensa reação do hospedeiro, sendo mais fácil a liberação mecânica das larvas.

Tabela 1

Número de larvas de Toxocara canis recuperadas segundo os órgāos avaliados e a técnica empregada. Sāo Paulo, 1995.

\begin{tabular}{c|c|c|c|c|c}
\hline \multicolumn{3}{c|}{ Técnica de digestão } & \multicolumn{3}{c}{ Técnica de homogeneização } \\
\hline$N^{N}$ animal & Fígado & Pulmão & $\mathrm{N}^{0}$ animal & Fígado & Pulmão \\
\hline 1 & 10 & 6 & 11 & 14 & 10 \\
\hline 2 & 20 & 0 & 12 & 50 & 0 \\
\hline 3 & 10 & 3 & 13 & 33 & 0 \\
\hline 4 & 3 & 3 & 14 & 63 & 13 \\
\hline 5 & 16 & 6 & 15 & 36 & 3 \\
\hline 6 & 6 & 3 & 16 & 23 & 6 \\
\hline 7 & 16 & 0 & 17 & 16 & 10 \\
\hline 8 & 10 & 6 & 18 & 30 & 6 \\
\hline 9 & 6 & 0 & 19 & 0 & 0 \\
\hline 10 & 10 & 0 & 20 & 0 & 5,80 \\
\hline $\bar{X}$ & 10,70 & 2,70 & $\bar{X}$ & 27,50 & 4,87 \\
\hline$s$ & 5,25 & 2,62 & $\mathrm{~s}$ & 19,06 & \\
\hline
\end{tabular}

$\overline{\mathrm{X}}=$ Média aritmética

$\mathrm{s}=$ Desvio padrão

\section{SUMMARY}

Two techniques, peptic digestion and homogenization, were tested for the recovering of Toxocara canis larvae from mice tissue Twenty mice were fed 1.000 embryonated eggs, and after 44-46 hours the animals were euthanised and liver and lungs were evaluated for the presence of larvae. Recovery rate from liver was greater than from lungs. Homogenization technique resulted in better percentage of larvae recovered, regardless of the organ evaluated.

UNITERMS: Toxocara canis: Larva migrans visceral; Larvae; Mouse; Animal tissues; Recovery; Techniques.

\section{AGRADECIMENTOS}

A Prof". Silvia Helena Venturoli Perri(UNI:SP-Araçatuba). pela análise estatistica.

\section{REFERÊNCIAS BIBLIOGRÁFICAS}

I-ABO-SHIHADA. M.N. AL-ZUBAIDY, B.A.: HFRBBRI, I, Tho migratlan al tarval foxocara canris in mice. I- Migration through the intesine in primary infection. Veterinary Parasitology - v.17. n. 1. p.65$73,1984$.
2-ABO-SHEHADA, M.V.: AL-ZUBBAIDY. H.A.; HITRBHERI. I V. Acyuired immunity to Toxescared remis infection in mice. Veterinary Parasitology

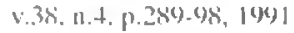

3-CONCLPPION, J.E., BARRIG iA, 0.0. Transfer of infection-induced immune protection to Toxocara canis infections in at mouse model

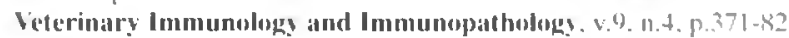
I)85.

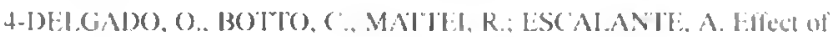
albendazol in experimental toxecariasis of mice. Annals of Tropical Vedicine and Parasitologg. v.8.3, 11.6, p.6.21-4, 1489.

5-1.F.E. H.I. 1-ffects of superinfection on the hehaviour of Fovecara camis latrvate in mice. Journal of Parasitolog! $1.46,11.5,0.583-8.1960$. 
6-MOREIRA, A.A.B. Aspectos imunopatológicos da Lanra migrans visceral causada por Toxocara canis. São Paulo, 1972. 104p. Tese (Doutorado). Instituto de Ciências Biomédicas, Universidade de São Paulo.

7-OSHIMA, T. Standardization of techniques for infecting mice with Toxocara canis and observations on the normal migration routes of the larvae. Journal of Parasitology, v. 47, n.4, p.652-6, I96I.

8-PIERGILI FIORETTI, D.; MORETTI, A.; MUGHETTI L.; BRUSCHI, F. Eosinophilia, granuloma formation, migratory behaviour of second larvae stage in murine Toxocara canis infection - effect of the inoculum size. Parassitologia, v. 31, p.153-66, 1989.

9-SCHANTZ, P.M.; GLICKMAN, L.T. Ascarids of dogs and cats: a problem of public health and veterinary medicine. Boletin de la Oficina Sanitaria Panamericana. v.94, n.6, p.571-86, 1983.

10-SPRENT, J.F.A. On the migratory behaviour of the larvae of various Ascaris species. Journal of Infectious Diseases, v.90, p. 165-76, 1952. 